\title{
Gynecological Surgery and Its Five Steps Towards Resilience: Minimally Invasive Approach in the COVID-19 Era
}

\author{
Inés Gil Prados, M.D. ${ }^{1}$, Mónica Bellón del Amo, M.D. ${ }^{2}$, Rebeca Ruiz Román, M.D. ${ }^{1}$, Francisco Javier García Santos, M.D. ${ }^{2}$ \\ Departments of ${ }^{1}$ Gynecology and Obstetrics, ${ }^{2}$ Gynecological Oncology and Low Genital Tract Pathology, Instituto de Salud de la Mujer del Hospital \\ Clínico San Carlos, Faculty of Medicine, Universidad Complutense de Madrid, Madrid, Spain
}

\begin{abstract}
After the declaration of the coronavirus disease 2019 (COVID-19) pandemic, gynecological surgery joins the readjustment process that this great global health crisis implies. In the light of current literature, the five steps towards its resilience are described as below; (1) Dynamic prioritization of surgical indications and reintroduction of elective surgeries: Diverse surgical prioritization lists are published including the most common gynecological pathologies. (2) Minimally invasive surgery through laparoscopy and robotic assistance: Some authors suggest a theoretical but unproven risk of viral transmission during these approaches because of the aerosol generation. These theories are opposed to the well-proven advantages of these approaches compared to open surgery. (3) Optimization of surgical procedures, according to the recommendations of different societies aimed at reducing the dispersion of aerosols and surgical smoke. (4) Clinical, epidemiological and microbiological screening of all patients awaiting prompt surgery: This screening should be adapted to the local alert state. (5) Protection through the reduction of number of persons present in the operating room, and the use of adapted personal protective equipment according to physical proximity to the patient.
\end{abstract}

Keywords: COVID-19, Gynecological surgery, Laparoscopy, Minimally invasive surgery, Robotic surgical procedures

This is an Open Access article distributed under the terms of the Creative Commons Attribution Non-Commercial License (http:// creativecommons.org/licenses/by-nc/4.0/) which permits unrestricted non-commercial use, distribution, and reproduction in any medium, provided the original work is properly cited.

\author{
Received November 9, 2020 \\ Revised November 27, 2020 \\ Accepted November 27, 2020 \\ Corresponding author \\ Inés Gil Prados \\ Department of Gynecology and \\ Obstetrics, Instituto de Salud de la \\ Mujer del Hospital Clínico San Carlos, \\ Faculty of Medicine, Universidad \\ Complutense de Madrid, Calle de \\ Sandoval 6, Escaleras Interiores, $5^{\circ}$ \\ Derecha, Madrid 28010, Spain \\ Tel: +34-958-20-91-25 \\ Fax: +34-692635483 \\ E-mail: inesgilpra@gmail.com \\ ORCID: \\ https://orcid.org/0000-0002-8192-2140
}

\section{INTRODUCTION}

On 31 December 2019, the World Health Organization receives notification of the first cases of pneumonia of unknown etiology detected in Hubei province. ${ }^{1}$ Shortly after, the coronavirus disease (COVID-19) pandemic is declared, a global health crisis that will break the health systems implemented to date from their foundations.

Within the broad health impact caused, gynecological surgery joins the readjustment process in respect of which, multiple societies establish consensus for action.
The five pillars of this process, the five steps towards resilience of a gynecological surgery that grows strong in the face of a world crisis, are described below.

\section{DYNAMIC PRIORITIZATION}

The first step is prioritization of surgical indications that require it, given the reserve of resources and infrastructure to cover the needs generated by care burden. It is a dynamically modified process depending on the epidemiological alert status.

The term MeNTs (medically necessary, time-sensitive) pro- 
cedure then arises, referring to those elective surgeries that were postponed, and the existence of a medical indication that continues to support them. Multiple authors defend the need to reintroduce such surgical activity, and point to the importance of prioritization criteria that guarantee equity in the rescheduling of the waiting lists generated. ${ }^{2,3}$

The Spanish Association of Surgeons $(A E C)^{4}$ suggests a prioritization scale of interventions according to percentage of hospitalization (Table 1).

Regarding COVID-19 positive patients without criteria for urgent surgery, a consensus is established on the postponement of surgery until the disappearance of the infection because of higher rates of mortality. ${ }^{5,6}$ Results from pilot studies suggest delaying the surgery for at least 4 weeks after a positive SARS-COV-2 test. ${ }^{7}$

\section{Pandemic phase}

During the pandemic phase, high surgical prioritization lists were published including the most common gynecological pathologies,

- Highest priority to gynecological emergencies and urgencies.

- High priority to oncological pathology: with the exception of certain advanced stages with the possibility of neoadjuvant treatment.

- Low priority or elective surgery: benign pathology with failure of conservative treatments.

\section{Towards the interpandemic phase}

In the current period of reintroduction of elective surgery, guidelines that also contemplate the management of benign pathology have been developed.

In the consensus made by The American Association of Gynecologic Laparoscopists and other societies, ${ }^{10}$ four levels were established in relation to the severity of the disease. Each of these levels is dichotomized according to the patient's comorbidity. In turn, the order of follow-up of this scale could be modified by the epidemiological risk of the moment and specific place of surgery (Table 2):

Table 1. Surgery dynamic prioritization scale $(A E C)^{4}$

\begin{tabular}{ll}
\hline I - Very low alert $\left(<5 \%^{*}\right)$ & Normal prioritization \\
II - Low alert $\left(5 \sim 25 \%^{*}\right)$ & $\begin{array}{c}\text { Emergencies, urgencies, malignity, } \\
\text { preferential benign indications }\end{array}$ \\
III - Medium alert $\left(25 \sim 50 \%^{*}\right)$ & $\begin{array}{l}\text { Emergencies, urgencies, malignity } \\
\text { IV - High alert }\left(50 \sim 75 \%^{*}\right)\end{array}$ \\
$\begin{array}{l}\text { Emergencies, urgencies } \\
\text { V - State of emergency }\left(>75 \%^{*}\right)\end{array}$ & Emergencies \\
\hline
\end{tabular}

*Percentage of hospitalization.
- Level 1: Low severity. Benign adnexal masses, controlled endometriosis, asymptomatic fibroids, abnormal uterine bleeding with low suspicion of malignancy and without anemia...

- A: Healthy patients.

- B: Risk patients according to ASA.

- Level 2: Intermediate severity. Symptomatic benign cysts, uncontrolled endometriosis, symptomatic fibroids, abnormal uterine bleeding with anemia, endometrial polyps if $>50$ years...

- A: Healthy patients.

- B: Risk patients according to ASA. In case of high epidemiological risk, consider prioritizing level 1A.

- Level 3: High severity. Suspicion of malignancy, deep endometriosis, bleeding with hemodynamic involvement...

- A: Healthy patients.

- B: Risk patients according to ASA. In case of high epidemiological risk, consider prioritizing level 2A.

- Level 4: Gynecological emergencies that cannot be postponed.

Other guidelines, such as the one published by the Royal College of Obstetricians and Gynecologist, establish the maximum surgical delay times according to priority (Table 2) ${ }^{11}$ :

- Level 1A (Emergencies, <24 hours): Ovarian torsion, sepsis originating from the genital tract, trauma to the genital tract, intra-abdominal bleeding, hemodynamically unstable miscarriage, unstable ectopic pregnancy, obstetric emergencies.

Table 2. Prioritization in the reintroduction of elective surgery (The American Association of Gynecologic Laparoscopists, Royal College of Obstetricians and Gynaecologist) ${ }^{10,11}$

\begin{tabular}{|c|c|}
\hline Emergencies (<24 h) & $\begin{array}{l}\text { Ovarian torsion } \\
\text { Unstable ectopic pregnancy } \\
\text { Hemoperitoneum } \\
\text { Sepsis }\end{array}$ \\
\hline Urgencies (<72 h) & $\begin{array}{l}\text { Pelvic or tubo-ovarian abscesses } \\
\text { Ectopic pregnancy } \\
\text { Postoperative complications }\end{array}$ \\
\hline High priority $\left(<4\right.$ weeks) ${ }^{*}$ & $\begin{array}{l}\text { Suspected malignancy } \\
\text { Confirmed malignancy }\end{array}$ \\
\hline Medium priority $\left(<3\right.$ months) ${ }^{*}$ & $\begin{array}{l}\text { Abnormal uterine bleeding with anemia } \\
\text { Endometriosis with intestinal involve- } \\
\text { ment or ureteral obstruction } \\
\text { Uncontrolled endometriosis }\end{array}$ \\
\hline Low priority (>3 months) & $\begin{array}{l}\text { Controlled endometriosis } \\
\text { Benign ovarian cysts } \\
\text { Abnormal uterine bleeding }\end{array}$ \\
\hline
\end{tabular}

*In case of high epidemiological alert, consider postponing surgery for risk patients and prioritizing lower levels. 
- Level 1B (Urgencies, <72 hours): Pelvic or tubo-ovarian abscesses that do not respond to antibiotic therapy, postoperative complications, stable ectopic pregnancy without hemoperitoneum, abortions that require surgical treatment.

- Level 2 (<4 weeks): Suspected or confirmed malignancy.

- Level 3 (<3 months): Fibroids causing anemia with failure of medical treatment, endometriosis with intestinal involvement or ureteral obstruction, uncontrolled endometriosis, hysterectomy due to abnormal bleeding and failure of medical treatment.

- Level 4 (>3 months): Tubal surgery, superficial or deep endometriosis without intestinal involvement or ureteral obstruction, fibroids without anemia, hysterectomy for abnormal uterine bleeding, benign ovarian cysts.

\section{MINIMAL INVASION}

There is much debate regarding the choice of the best surgical approach during the COVID-19 pandemic, since laparoscopy and robotic assistance are considered possible aerosol-generating procedures (AGP).

There could be a theoretical but unproven risk of viral transmission during these approaches ${ }^{12,13}$ :

- Airway: through the generation of aerosols and surgical smoke, which by extrapolation of data from other infections, could contain viral particles.

- Blood contact: presence of viral RNA in blood in $1 \sim 15 \%$ of patients.

The high infectivity of peritoneal fluids has also been recently

Table 3. Advantages of minimally invasive surgery compared to open approach

Lower morbidity and hospital stay

Surgical smoke containment

Physical distance between surgeons and patient described, where high concentrations of viral RNA have been detected, even more than in naso or oropharyngeal exudates. ${ }^{14}$

\section{Minimal invasion in gynecology}

Despite controversies generated regarding risk of aerosolization, the available evidence is scarce, and the minimally invasive approach has been considered of choice by various scientific societies for most indications in gynecology (Table 3). ${ }^{15,16}$

As an exception to this, and given the greater probability of viral presence in the digestive tube due to aspiration of nasopharyngeal secretions, there is consensus on the recommendation of an open approach in cases of surgery with intestinal involvement (endometriosis of the rectovaginal septum, tubo-ovarian abscesses...). ${ }^{17,18}$

On the other hand, there are authors who refer to a greater safety of robot assisted surgery compared to laparoscopy: need for lower intra-abdominal CO2 pressures for optimal vision, need for fewer staff in the operating room, more physical distance to the patient (Table 4$){ }^{19}$

\section{OPTIMIZATION}

Given the nature of the aerosol-generating procedure associated with the creation of pneumoperitoneum, there is consensus on adopting multiple precautions to reduce exposure to $\mathrm{CO} 2$ and

Table 5. Recommendations and rules during laparoscopic procedures in times of COVID-19

\begin{tabular}{ll}
\multicolumn{1}{c}{ Recommendations } & \multicolumn{1}{c}{ Mandatory rules } \\
\hline $\begin{array}{l}\text { Low pneumoperitoneal pressures } \\
\text { Selective use of electrosurgical } \\
\text { devices }\end{array}$ & Use balloon trocars \\
\hline $\begin{array}{c}\text { Avoid sudden losses of } \\
\text { pneumoperitoneum }\end{array}$ & Evacuation and filtering systems \\
\hline
\end{tabular}

Table 4. Surgical approaches during the COVID-19 pandemic ${ }^{19}$

\begin{tabular}{ccc}
\hline Open surgery & Robot assisted surgery & Laparoscopy \\
\hline Less generation of aerosols & Generation of aerosols (contained and filtered) & Generation of aerosols (contained and filtered) \\
Dispersion and maximum exposure to surgical smoke & Smoke containment and filters & Smoke containment and filters \\
No intra-abdominal pressure & Intra-abdominal pressure: $<10 \mathrm{mmHg}$ & Intra-abdominal pressure: $10 \sim 15 \mathrm{mmHg}$ \\
Major blood contamination & Large robot surface & Less blood contamination \\
Large number of surgical instruments & Less blood contamination & Limited surgical instruments \\
3 Bedside assistants & Limited surgical instruments & 3 Bedside assistants \\
Longer hospital stay & 2 Bedside assistants and 1 console surgeon & Short hospital stay
\end{tabular}


surgical smoke. ${ }^{5,20}$

Moments of greatest risk of transmission are those related to the dispersion of aerosols:

- Creation and desufflation of pneumoperitoneum.

- Placement and removal of trocars.

- Instrument exchange.

- Specimen extraction.

With all of the above, some mandatory rules and other specific recommendations have been implemented in our environment during the course of laparoscopic and robotic assisted surgery (Table 5):

- Selective use of electrosurgical devices in order to minimize the production of smoke, with low-power setting and reduced cutting and coagulation times. Avoid using an ultrasonic scalpel (aerosol generation).

- Incorporation of evacuation and filtering systems with capacity to contain microaerosols.

- Evacuation of pneumoperitoneum with laparoscopic suction before trocars and specimen extraction.

- Minimize pneumoperitoneal pressures (10 12 mmHg). Greater capacity of such decrease in robotic surgery.

- Use of high-capacity access ports to keep the pneumoperitoneum sealed. Balloon trocars are of choice.

In gynecological surgery, special precaution before the extraction of large surgical specimens. The European Society for Gyneacological Endoscopy, warns about the significant dispersion of $\mathrm{CO} 2$ during laparoscopic hysterectomy.

\section{SCREENING}

The Spanish Association of Surgeons (AEC) establishes screening recommendations depending on the epidemiological situation according to the five alert states mentioned previously (Table 1$).{ }^{4}$

o Clinical and epidemiological evaluation of all patients awaiting prompt surgery, without need for physical presence and not dependent on the alert state of the population:

- Questionnaire about contact with positive cases in the last 14 days. Physical distancing and protection measures are recommended during the two weeks prior to admission.

- Questionnaire about suspicious signs and symptoms according to the World Health Organization: fever, dry cough, tiredness, shortness of breath, muscle aches, loss of taste or smell, sore throat, diarrhea, nausea, vomiting ${ }^{21}$...

Repeating both screenings is recommended in the 48 72 hour period prior to surgery.

o Microbiological evaluation conditioned by the local alert state. The collection of nasopharyngeal exudate and PCR is established as the test of choice, with a high specificity. Sample collection is recommended within 72 hours prior to surgery.
- Alert state II or higher and high risk patient: clinicalepidemiological and microbiological screening.

- Alert state I and intermediate risk patient: clinical-epidemiological screening.

- Alert state I and low risk patient: clinical-epidemiological screening without need for repetition in the 72 hours prior to surgery.

The routine use of analytical and imaging tests is not recommended. On the other hand, serological tests are proposed in cases of suspected active infection with PCR negativity, without a clear indication, pending studies that currently seem to reveal encouraging results regarding their usefulness. ${ }^{22,23}$

\section{PROTECTION}

Use of adapted personal protective equipment according to screening results and physical proximity to the patient. Furthermore, the need to limit the number of persons in the operating room is highlighted.

Recommendations in COVID positive patients or suspected infection, when surgery cannot be postponed, are as follows ${ }^{1924,25}$ :

$\checkmark$ "Bedside assistants": Level III protection. Work uniform, surgical cap, well-fitted medical protective mask FFP2/3, long-sleeved latex gowns and gloves, full-face respiratory protective devices.

$\checkmark$ Surgeon at console: Level II protection. Work uniform, surgical cap, well-fitted medical protective mask FFP2/3, longsleeved latex gowns and gloves, goggles.

\section{CONCLUSION}

Laparoscopy finds an essential role in the establishment of gynecological surgery in the midst of the COVID-19 pandemic, being easily integrated into it by the five steps towards its resilience: prioritization, minimal invasion, optimization, screening and protection.

\section{ORCID}

Inés Gil Prados, https://orcid.org/0000-0002-8192-2140

Mónica Bellón del Amo, https://orcid.org/0000-0001-9039-9921

Rebeca Ruiz Román, https://orcid.org/0000-0002-5866-8711

Francisco Javier García Santos,

https://orcid.org/0000-0002-8388-0319

\section{AUTHORS' CONTRIBUTIONS}

Conceptualization: Francisco Javier García Santos, Mónica Bellón del Amo. Formal analysis: Inés Gil Prados. Methodology: Inés Gil Prados, Francisco Javier García Santos. Writing-original 
draft: Inés Gil Prados, Francisco Javier García Santos. Writingreview and editing: Inés Gil Prados, Rebeca Ruiz Román.

\section{CONFLICT OF INTEREST}

None.

\section{FUNDING}

None.

\section{ACKNOWLEDGMENTS}

None.

\section{REFERENCES}

1) World Health Organization. Timeline of WHO's response to COVID-19 [Internet]. World Health Organization; 2020 [cited on 2020 Oct. 13]. Available from: https://www.who.int/news/item/2906-2020-covidtimeline.

2) Prachand VN, Milner R, Angelos P, et al. Medically Necessary, TimeSensitive Procedures: Scoring System to Ethically and Efficiently Manage Resource Scarcity and Provider Risk During the COVID-19 Pandemic. J Am Coll Surg 2020;231:281-288.

3) Odejinmi F, Clark TJ, Mallick R. Getting back to business: considerations for restarting non-cancer gynaecological surgery following the COVID-19 peak. Facts Views Vis Obgyn 2020;12:119-127.

4) Asociación Española de Cirujanos (AEC), Sociedad Española de Anestesiología y Reanimación (SEDAR), Sociedad Española de Medicina Preventiva SPeHS, Sociedad Española de Enfermedades Infecciosas y Microbiología Clínica (SEIMC), Asociación Española de Enfermería Quirúrgica (AEEQ). RECOMENDACIONES PARA LA PROGRAMACIÓN DE CIRUGÍA EN CONDICIONES DE SEGURIDAD DURANTE EL PERIODO DE TRANSICIÓN DE LA PANDEMIA COVID-19 [Internet]. Asociación Española de Cirujanos (AEC); 2020. Available from: https://www.aecirujanos.es/files/ portalcontenidos/525/documentos/cirugia-covid19.pdf.

5) Joint Statement on Minimally Invasive Gynecologic Surgery during the COVID-19 Pandemic. J Minim Invasive Gynecol 2020;27:10271029.

6) COVIDSurg Collaborative. Mortality and pulmonary complications in patients undergoing surgery with perioperative SARS-CoV-2 infection: an international cohort study. Lancet 2020;396:27-38.

7) COVIDSurg Collaborative. Delaying surgery for patients with a previous SARS-CoV-2 infection. Br J Surg 2020;107:e601-e602.

8) Akladios C, Azais H, Ballester M, et al. [Guidelines for surgical management of gynaecological cancer during pandemic COVID-19 period - FRANCOGYN group for the CNGOF]. Gynecol Obstet Fertil Senol 2020;48:444-447. [Article in French]
9) Chiofalo B, Baiocco E, Mancini E, et al. Practical recommendations for gynecologic surgery during the COVID-19 pandemic. Int J Gynaecol Obstet 2020;150:146-150.

10) Joint Statement on Re-introduction of Hospital and Office-based Procedures for the Practicing Urogynecologist and Gynecologist. J Minim Invasive Gynecol 2020;27:1030-1032.

11) Royal College of Obstetricians and Gynaecologists. Restoration and Recovery: Priorities for Obstetrics and Gynaecology. A prioritisation framework for care in response to COVID-19 [Internet]. London: Royal College of Obstetricians and Gynaecologists; 2020 [cited on 2020 Oct. 13]. Available from: https://www.rcog.org.uk/globalassets/ documents/guidelines/2020-05-29-restoration-and-recovery---priorities-for-obstetrics-and-gynaecology.pdf.

12) Alp E, Bijl D, Bleichrodt RP, Hansson B, Voss A. Surgical smoke and infection control. J Hosp Infect 2006;62:1-5.

13) Mallick R, Odejinmi F, Clark TJ. Covid 19 pandemic and gynaecological laparoscopic surgery: knowns and unknowns. Facts Views Vis Obgyn 2020;12:3-7.

14) Coccolini F, Tartaglia D, Puglisi A, et al. SARS-CoV-2 Is Present in Peritoneal Fluid in COVID-19 Patients. Ann Surg 2020;272:e240e242.

15) Morris SN, Fader AN, Milad MP, Dionisi HJ. Understanding the "Scope" of the Problem: Why Laparoscopy Is Considered Safe during the COVID-19 Pandemic. J Minim Invasive Gynecol 2020;27:789791.

16) Thomas V, Maillard C, Barnard A, et al. International Society for Gynecologic Endoscopy (ISGE) guidelines and recommendations on gynecological endoscopy during the evolutionary phases of the SARSCoV-2 pandemic. Eur J Obstet Gynecol Reprod Biol 2020;253:133140.

17) Royal College of Obstetricians and Gynaecologists, British Society for Gynaecological Endoscopy. Joint RCOG / BSGE Statement on gynaecological laparoscopic procedures and COVID-19 [Internet]. London: Royal College of Obstetricians and Gynaecologists, British Society for Gynaecological Endoscopy. 2020 [cited on 2020 Sep. 29]. Available from: https://mk0britishsociep8d9m.kinstacdn.com/wp-content/ uploads/2020/03/Joint-RCOG-BSGE-Statement-on-gynaecologicallaparoscopic-procedures-and-COVID-19.pdf.

18) ESGE Recommendations for Gynaecological Endoscopic Surgery for COVID-19 Outbreak. Facts Views Vis Obgyn 2020;12:5.

19) Kimmig R, Verheijen RHM, Rudnicki M, Society of European Robotic Gynaecological Surgery(SERGS) Council. Robot assisted surgery during the COVID-19 pandemic, especially for gynecological cancer: a statement of the Society of European Robotic Gynaecological Surgery (SERGS). J Gynecol Oncol 2020;31:e59.

20) Gracia M, Rius M, Carmona F. [Laparoscopic surgery in the COVID-19 era]. Clin Invest Ginecol Obstet 2020;47:106-110. [Article in Spanish]

21) World Health Organization. Coronavirus. Symptoms. [Internet]. World Health Organization; 2020. Available from: https://www.who. 
int/health-topics/coronavirus\#tab=tab_3.

22) Centro Superior de Investigaciones Científicas (CSIC). Principales novedades internacionales sobre DIAGNÓSTICO Y CONTENCIÓN. Newsletter PTI Salud Global/Global Health Cov19 (JULIO 2020) [Internet]. Centro Superior de Investigaciones Científicas (CSIC); 2020 [cited on 2020 Oct. 31]. Available from: https://pti-saludglobalcovid19.corp.csic.es/wp-content/uploads/2020/08/Novedades_Internacionales_COVID19_JUL.pdf.

23) Rongqing Z, Li M, Song H, et al. Early Detection of Severe Acute Respiratory Syndrome Coronavirus 2 Antibodies as a Serologic Marker of Infection in Patients With Coronavirus Disease 2019. Clin Infect Dis 2020;71:2066-2072.
24) Liang T. Handbook of COVID-19 Prevention and Treatment [Internet]. Hangzhou: Zhejiang University School of Medicine; 2020 [cited on 2020 Oct. 15]. Available from: https://esge.org/documents/Handbook_of_COVID-19_Prevention_and_Treatment.pdf.

25) European Centre for Disease Prevention and Control. Infection prevention and control for COVID-19 in healthcare settings - first update (12 March 2020) [Internet]. Stockholm: European Centre for Disease Prevention and Control; 2020 [cited on 2020 Oct. 15]. Available from: https://www.ecdc.europa.eu/sites/default/files/documents/ COVID-19-infection-prevention-and-control-healthcare-settingsmarch-2020.pdf. 